\title{
Article \\ Effect of Thermal Annealing on the Photoluminescence of Dense Si Nanodots Embedded in Amorphous Silicon Nitride Films
}

\author{
Qianqian Liu (D, Xiaoxuan Chen, Hongliang Li *, Yanqing Guo, Jie Song, Wenxing Zhang, Chao Song, Rui Huang \\ and Zewen Lin *(D)
}

check for updates

Citation: Liu, Q.; Chen, X.; Li, H.; Guo, Y.; Song, J.; Zhang, W.; Song, C.; Huang, R.; Lin, Z. Effect of Thermal Annealing on the Photoluminescence of Dense Si Nanodots Embedded in Amorphous Silicon Nitride Films. Micromachines 2021, 12, 354 https://doi.org/10.3390/mi12040354

Academic Editor: Hieu Pham Trung Nguyen

Received: 27 January 2021

Accepted: 22 March 2021

Published: 25 March 2021

Publisher's Note: MDPI stays neutral with regard to jurisdictional claims in published maps and institutional affiliations.

Copyright: (c) 2021 by the authors. Licensee MDPI, Basel, Switzerland. This article is an open access article distributed under the terms and conditions of the Creative Commons Attribution (CC BY) license (https:/ / creativecommons.org/licenses/by/ $4.0 /)$.
School of Materials Science and Engineering, Hanshan Normal University, Chaozhou 521041, China; 2018267230@stu.hstc.edu.cn (Q.L.); 2018267226@stu.hstc.edu.cn (X.C.); yqguo126@126.com (Y.G.); songjie@hstc.edu.cn (J.S.); wenxingzhang@hstc.edu.cn (W.Z.); songchao511@126.com (C.S.); rhuang@hstc.edu.cn (R.H.)

* Correspondence: lihl4@hstc.edu.cn (H.L.); zewenlin@126.com (Z.L.)

\begin{abstract}
Luminescent amorphous silicon nitride-containing dense Si nanodots were prepared by using very-high-frequency plasma-enhanced chemical vapor deposition at $250{ }^{\circ} \mathrm{C}$. The influence of thermal annealing on photoluminescence (PL) was studied. Compared with the pristine film, thermal annealing at $1000{ }^{\circ} \mathrm{C}$ gave rise to a significant enhancement by more than twofold in terms of PL intensity. The PL featured a nanosecond recombination dynamic. The PL peak position was independent of the excitation wavelength and measured temperatures. By combining the Raman spectra and infrared absorption spectra analyses, the enhanced PL was suggested to be from the increased density of radiative centers related to the Si dangling bonds (K0) and $\mathrm{N}_{4}{ }^{+}$or $\mathrm{N}_{2}{ }^{0}$ as a result of bonding configuration reconstruction.
\end{abstract}

Keywords: photoluminescence; thin films; optical properties; $\mathrm{SiNx}$

\section{Introduction}

Si nanostructures embedded in wide-bandgap dielectrics show great promise in realizing efficient Si-based light sources compatible with the mainstream complementary metal-oxide semiconductor (CMOS) technology [1-6]. Compared with the wide bandgap of silicon oxide, amorphous silicon nitride (a-SiNx) shows a narrower and tunable bandgap ranging from $\sim 2 \mathrm{eV}$ to $\sim 5 \mathrm{eV}$. This characteristic allows more carriers to easily be injected into the Si nanostructures, thereby making a-SiNx favorable for designing stable and efficient SiN-based light-emitting devices (LEDs) at low driving voltages [7-9]. The structure and optoelectronic properties of Si nanostructures embedded in SiNx matrix have been extensively studied. Using high-density nanostructures is an effective way to obtain highly efficient light emission [10,11]. However, developing more efficient SiN-based LEDs is still a huge challenge. Many nonradiative recombination centers caused by structural distortions and defects in the a-SiNx matrix lead to the deterioration of luminescence process [12]. In particular, the large surface-to-volume ratio of Si nanostructures makes surface states play a more important role in the luminescence performance $[13,14]$. Therefore, the engineering of Si nanostructures through surface modification has become a key issue for obtaining efficient SiN-based devices with suppressed nonradiative recombination centers.

In earlier studies, we fabricated amorphous Si nanostructures with a density of over $4.6 \times 10^{12} / \mathrm{cm}^{2}$ embedded in SiNx matrix by very-high-frequency plasma-enhanced chemical vapor deposition technique (VHF-PECVD) [11]. The dense Si nanostructures can be both optically and electrically excited and emit strong light emission. In the current work, the effect of thermal annealing on the photoluminescence of Si nanostructures embedded in SiNx was investigated. Thermal annealing notably improved the photoluminescence (PL). The enhanced PL is discussed in detail based on its annealing behavior. 


\section{Experiment}

The a-SiNx films containing dense amorphous Si nanodots were fabricated by VHF$\mathrm{PECVD}$ at $250{ }^{\circ} \mathrm{C}$ using the gas mixture of $\mathrm{SiH} 4, \mathrm{NH} 3$, and $\mathrm{H} 2$ as the precursor, as demonstrated previously [11]. After deposition, the films were first dehydrogenated at $400{ }^{\circ} \mathrm{C}$ and then thermally annealed at different temperatures in $\mathrm{N}_{2}$ atmosphere for $60 \mathrm{~min}$. The microstructure of samples was characterized by the Horiba LabRAM HR Evolution Raman Spectrometer. The PL spectra of the films were measured by a Jobin Yvon FluoroLog-3 spectrophotometer equipped with a $450 \mathrm{~W}$ steady Xe lamp. PL decay curves were recorded on an Edinburgh FLS1000 spectrometer using a $372 \mathrm{~nm}$ picosecond laser (pulse width $44 \mathrm{ps,}$ repetition rate $=20 \mathrm{MHz}$ ). The decay rates were measured at the wavelength of $570 \mathrm{~nm}$. The time response of the detector and the electronics used in the PL decay measurements was less than $400 \mathrm{ps}$. The bonding configurations of the films were recorded using a Fourier-transform infrared (FTIR) spectroscope (Shimadzu IR Pretige-21).

\section{Results and Discussion}

Figure 1 presents the PL spectra of the pristine and annealed samples excited by $325 \mathrm{~nm}$ line from a Xe lamp. The spectrum of the pristine sample showed a broad band centered at $570 \mathrm{~nm}$ with a shoulder at $425 \mathrm{~nm}$. The spectral shape of the PL peak did not change with increasing annealing temperature. However, the PL intensity rapidly increased with increasing annealing temperature from $400{ }^{\circ} \mathrm{C}$ to $1000{ }^{\circ} \mathrm{C}$. Compared with the pristine film, it was interesting to find that thermal annealing at $1000^{\circ} \mathrm{C}$ gave rise to a significant enhancement by more than twofold in the green PL.

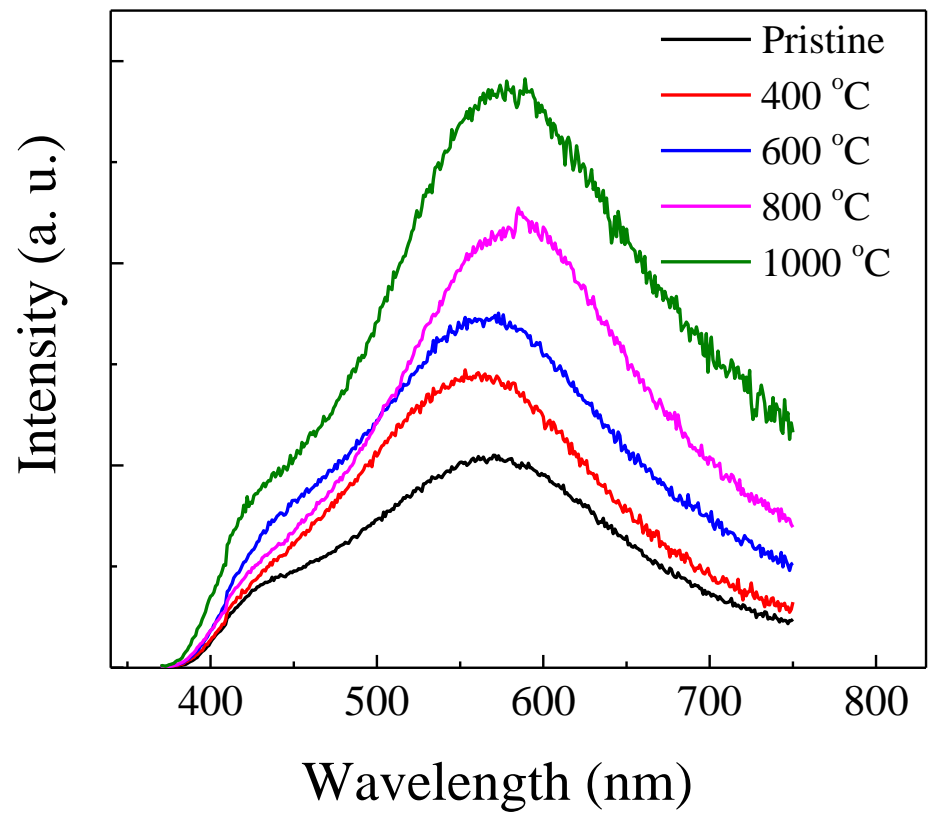

Figure 1. Photoluminescence (PL) spectra of the pristine and annealed samples excited by $325 \mathrm{~nm}$ line from a Xe lamp.

To analyze the enhanced PL behavior, the microstructure of the samples was characterized. Figure 2a shows the Raman spectra of the samples with and without annealing. All Raman spectra displayed a broad band between $100 \mathrm{~cm}^{-1}$ and $600 \mathrm{~cm}^{-1}$. The broad Raman band can be decomposed into four peaks located at $\sim 110 \mathrm{~cm}^{-1}, \sim 370 \mathrm{~cm}^{-1}, \sim 450 \mathrm{~cm}^{-1}$, and $\sim 480 \mathrm{~cm}^{-1}$, which were attributed to the transverse-acoustic (TA), the longitude-acoustic (LA), the longitudinal-optical (LO), and the transverse-optical (TO) vibration mode of amorphous silicon, respectively [15]. This indicated that no Si nanocrystals were produced in the samples, even after they were annealed at $1000^{\circ} \mathrm{C}$. The Transmission Electron Microscope (TEM) image shown in Figure $2 b$ further reveals that the structure of Si nanodots is amorphous. Therefore, the improved PL from the annealed samples did not result from 
the Si nanocrystals. As was revealed by atomic force microscopy (AFM), one can see that there was no obvious change in the surface morphology between pristine and annealed sample at $1000{ }^{\circ} \mathrm{C}$ (Figure 2c,d). This excluded the possibility that the enhanced PL is the result of the increase in light extraction from the annealed samples.
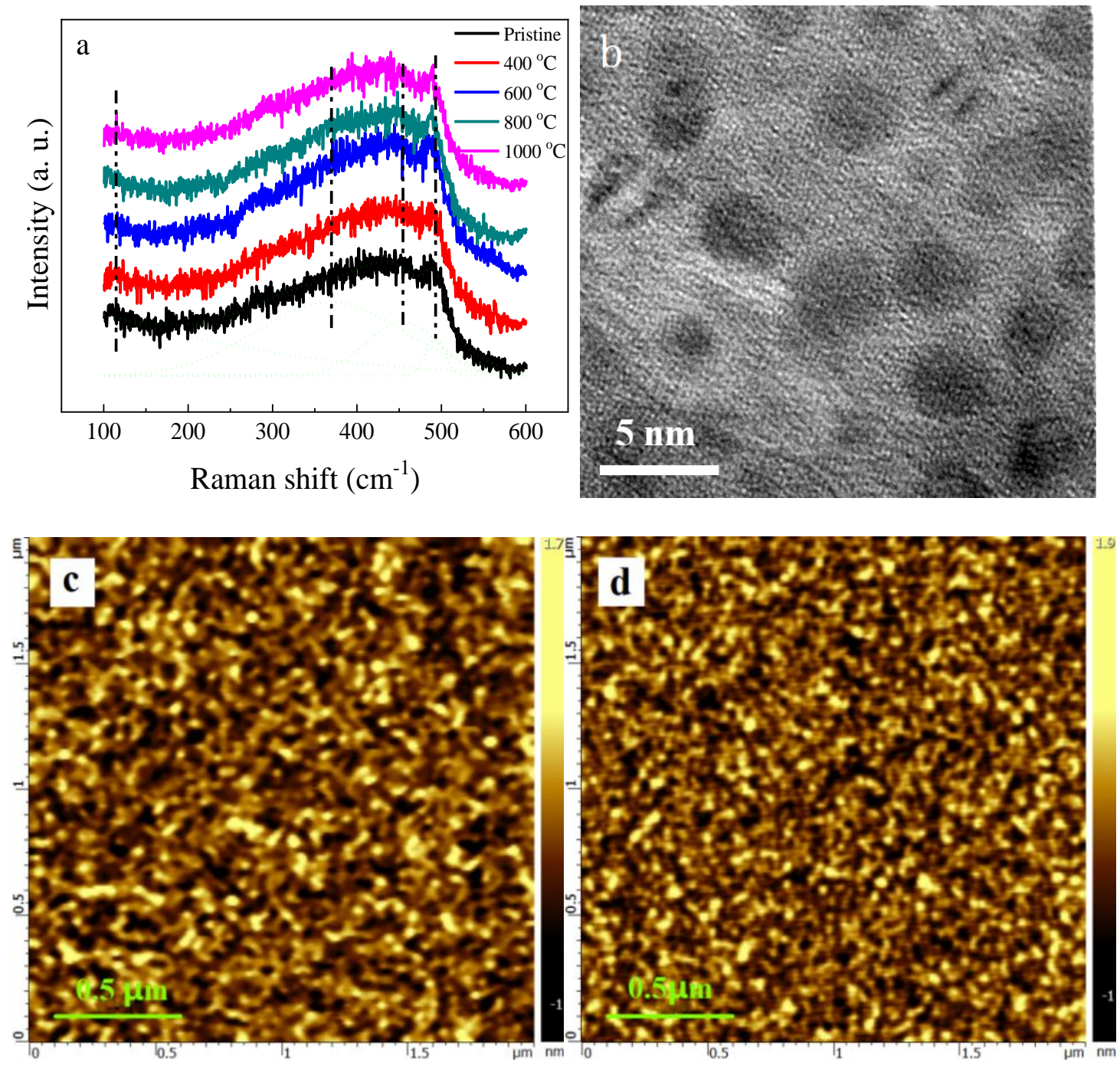

Figure 2. (a) Raman spectra of the samples with and without annealing; (b) Bright-field TEM image of the dense Si nanodots; (c) Atomic force microscopy (AFM) images of the pristine sample; (d) AFM images of the sample annealed at $1000{ }^{\circ} \mathrm{C}$.

To examine the local bonding configurations of the samples, FTIR was employed. Figure 3a displays typical FTIR absorption spectra of the samples. These spectra demonstrated the following vibrational bands. The intense absorption band at $845 \mathrm{~cm}^{-1}$ was associated with the Si-N stretching mode [16]. The absorption band at $2140 \mathrm{~cm}^{-1}$ bands was connected to $\mathrm{Si}-\mathrm{H}$ stretching mode. [16] The $3350 \mathrm{~cm}^{-1}$ band corresponded to the $\mathrm{N}-\mathrm{H}$ stretching mode [16]. The evident feature in the FTIR spectra was that the signals of the $\mathrm{Si}-\mathrm{H}$ and the $\mathrm{N}-\mathrm{H}$ vibrations strongly depend on the annealing temperatures. The ratios of $\mathrm{Si}-\mathrm{H} / \mathrm{Si}-\mathrm{N}$ and $\mathrm{N}-\mathrm{H} / \mathrm{Si}-\mathrm{N}$ deduced from the IR absorption coefficient decreased gradually with increasing annealing temperature from $400{ }^{\circ} \mathrm{C}$ to $1000{ }^{\circ} \mathrm{C}$, as displayed in Figure 4. Comparing the FTIR spectra with the PL spectra, it was evident that the behavior of the PL intensity with the annealing temperature exhibited a trend opposite to that of the $\mathrm{Si}-\mathrm{H} / \mathrm{Si}-\mathrm{N}$ and $\mathrm{N}-\mathrm{H} / \mathrm{Si}-\mathrm{N}$ ratio with the annealing temperature. This finding implied that the increase of the emission intensity was closely associated with the chemical bond reconstruction and was especially closely related to the decreasing concentration of 
$\mathrm{Si}-\mathrm{H}$ and $\mathrm{N}-\mathrm{H}$ bonds. In fact, the decrease in the concentration of $\mathrm{Si}-\mathrm{H}$ and $\mathrm{N}-\mathrm{H}$ bonds indicated the fracture of $\mathrm{Si}-\mathrm{H}$ and $\mathrm{N}-\mathrm{H}$ bonds and an increase in the concentration of $\mathrm{Si}$ and $\mathrm{N}$ dangling bonds. Therefore, the increasing concentration of $\mathrm{Si}$ and $\mathrm{N}$ dangling bonds in our case seemed to play an important role in the significant enhancement in the 570 and $425 \mathrm{~nm}$ PL.

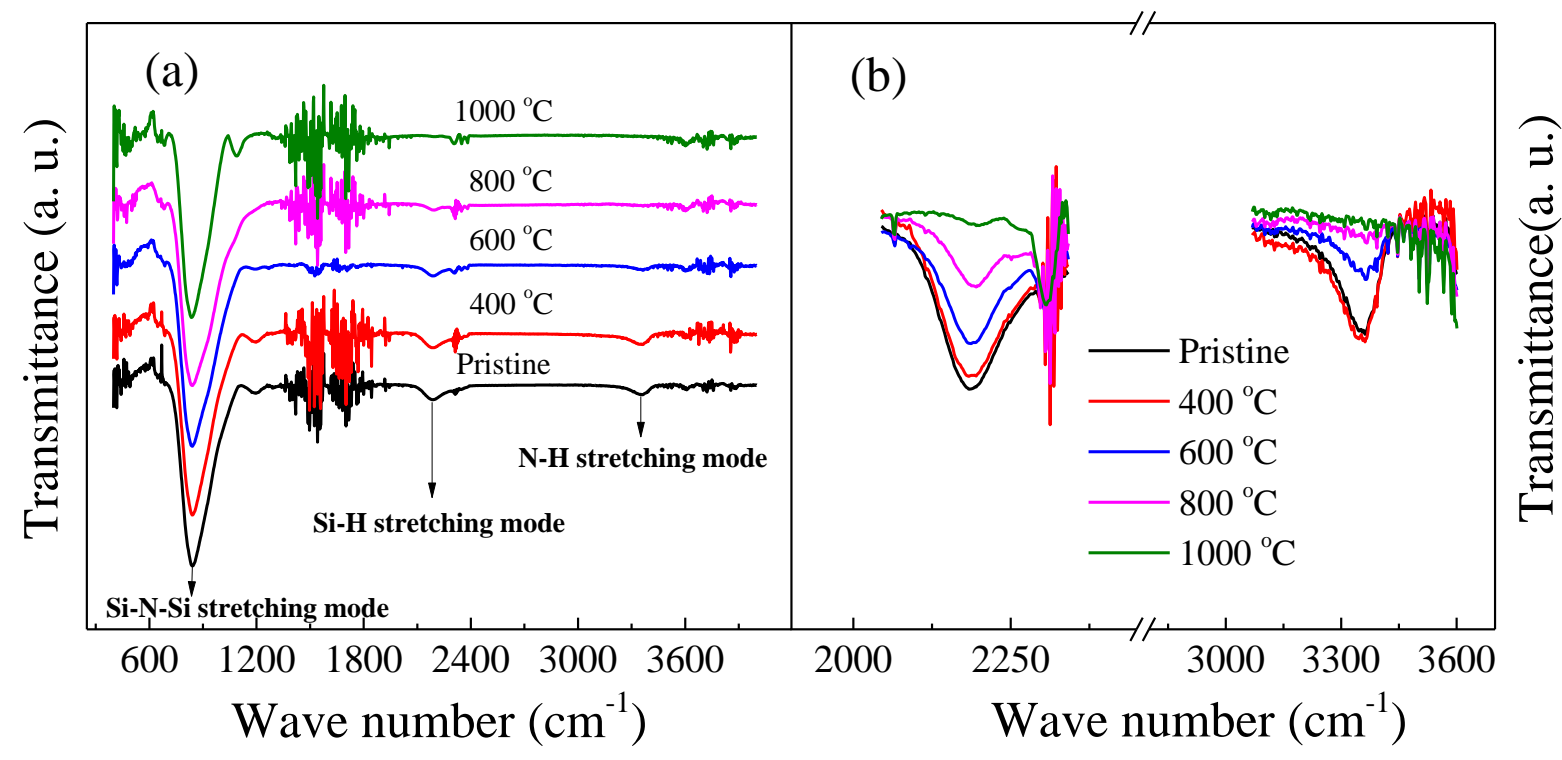

Figure 3. (a) FTIR absorption spectra of the samples; (b) The absorption band at $2140 \mathrm{~cm}^{-1}$ and $3350 \mathrm{~cm}^{-1}$, respectively.

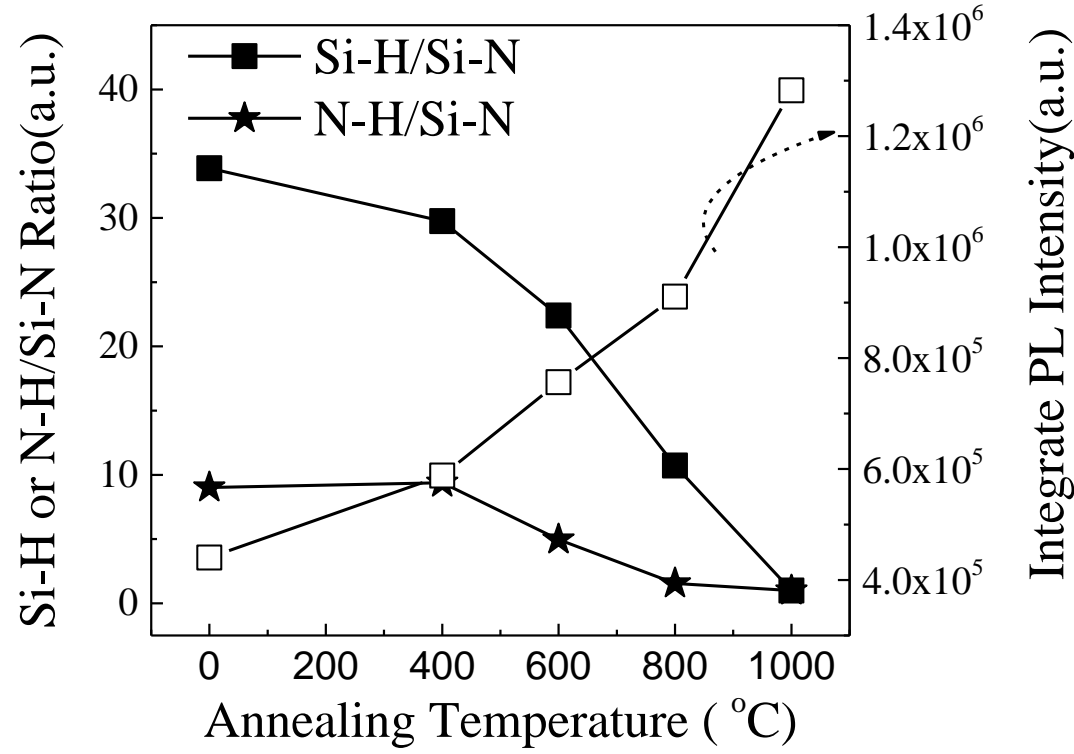

Figure 4. The ratios of $\mathrm{Si}-\mathrm{H} / \mathrm{Si}-\mathrm{N}$ and $\mathrm{N}-\mathrm{H} / \mathrm{Si}-\mathrm{N}$ deduced from the IR absorption coefficient as a function of annealing temperature.

To further understand the enhanced PL characteristics, PL (570 nm) decay curves were taken from the samples excited by a $372 \mathrm{~nm}$ picosecond laser, as illustrated in Figure 5. All the PL decay curves can be fitted by a two-exponent function, as demonstrated in the following [17]:

$$
I(t)=I_{0}+I_{1} \exp \left(\frac{-t}{\tau_{1}}\right)+I_{2} \exp \left(\frac{-t}{\tau_{2}}\right)
$$

where $I_{0}$ is the background level, and $I_{\mathrm{i}}$ and $\tau_{\mathrm{i}}(i=1,2)$ are the corresponding weight fraction and lifetime of each exponential decay component, respectively. The intensity-weighted 
averaged PL lifetimes are then determined by $\left(A_{1} * \tau_{1}^{2}+A_{2} * \tau_{2}^{2}\right) /\left(A_{1} * \tau_{1}+A_{2} * \tau_{2}\right)$. As demonstrated in Figure 5, all samples featured a fast decay dynamic with the lifetimes of $\sim 1$ ns. Generally speaking, annealing at high temperatures can effectively passivate the surface state of silicon nanostructures to a certain extent, thereby making the PL lifetime longer, as well as producing the PL enhancement. However, the lifetimes in our case were independent of annealing temperatures. This indicated that the enhancement of PL did not come from the improved surface state passivation of Si nanostructures in our case. In fact, such a luminescent dynamic behavior was the same as that observed in the defect-related luminescent a-SiN ${ }_{x}[13,14]$. According to Robertson and Powell, in the case of a-SiNx, the radiative recombination at $\mathrm{Si}$ dangling bonds $(\mathrm{K} 0)$ would give rise to $570 \mathrm{~nm}$ PL, whereas the radiative recombination either from the conduction band to the $\mathrm{N}_{2}{ }^{0}$ level or the valence band to the $\mathrm{N}_{4}{ }^{+}$level would result in $\sim 430 \mathrm{~nm}$ PL [18]. Therefore, the improved PL was considered to originate from the increased density of radiative centers related to the $\mathrm{Si}$ dangling bonds (K0) and $\mathrm{N}_{4}{ }^{+}$or $\mathrm{N}_{2}{ }^{0}$ as a result of bonding configuration reconstruction, as revealed in Figure 4. To gain more insight into the enhanced PL characteristics, the sample annealed at $1000{ }^{\circ} \mathrm{C}$ was excited by different wavelengths, as shown in Figure 6 . The PL positions almost showed no recognized changes with increasing excitation wavelength from $280 \mathrm{~nm}$ to $340 \mathrm{~nm}$. Furthermore, the PL peak position excited by the $325 \mathrm{~nm}$ line was independent of the temperature, as illustrated in Figure 7. These results excluded the possibility that the 570 and $425 \mathrm{~nm}$ PL emissions were from band-to-band recombination in Si nanodots, further indicating that the PL arises from defect-related luminescence centers. Therefore, based on the above results, the enhanced emission can be attributed to the increased density of radiative centers related to the Si dangling bonds (K0) and $\mathrm{N}_{4}{ }^{+}$or $\mathrm{N}_{2}{ }^{0}$ in a-SiNx.

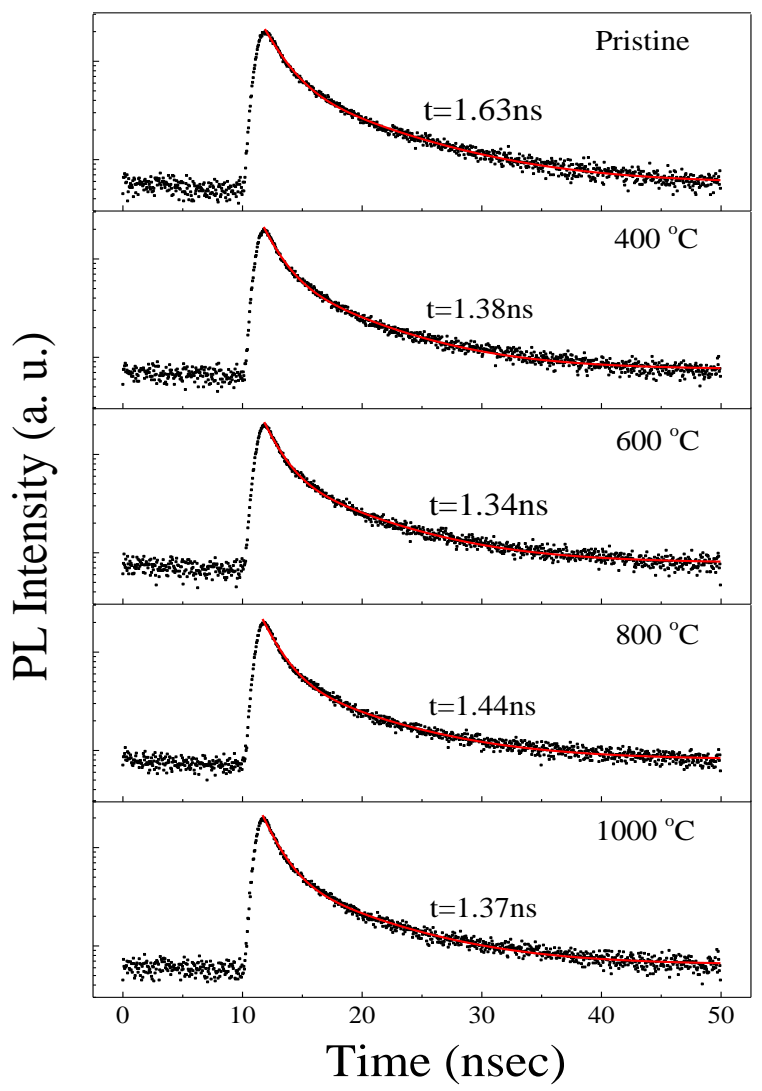

Figure 5. PL decay curves for all samples. 


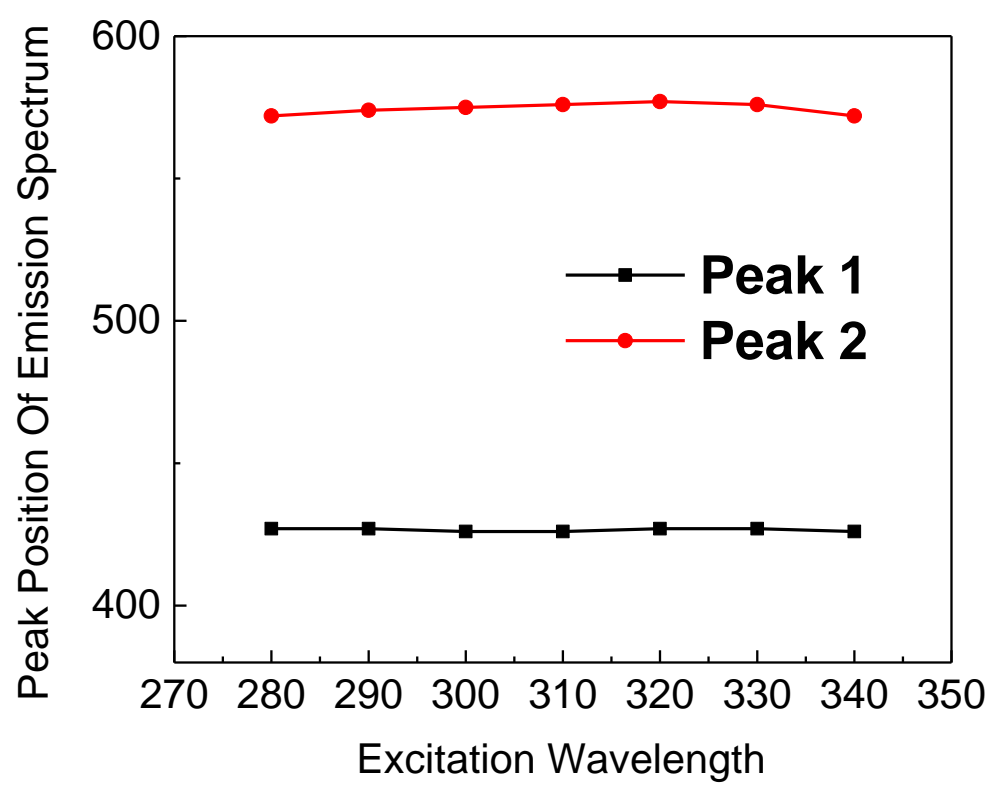

Figure 6. The PL positions as a function of the excitation wavelength.

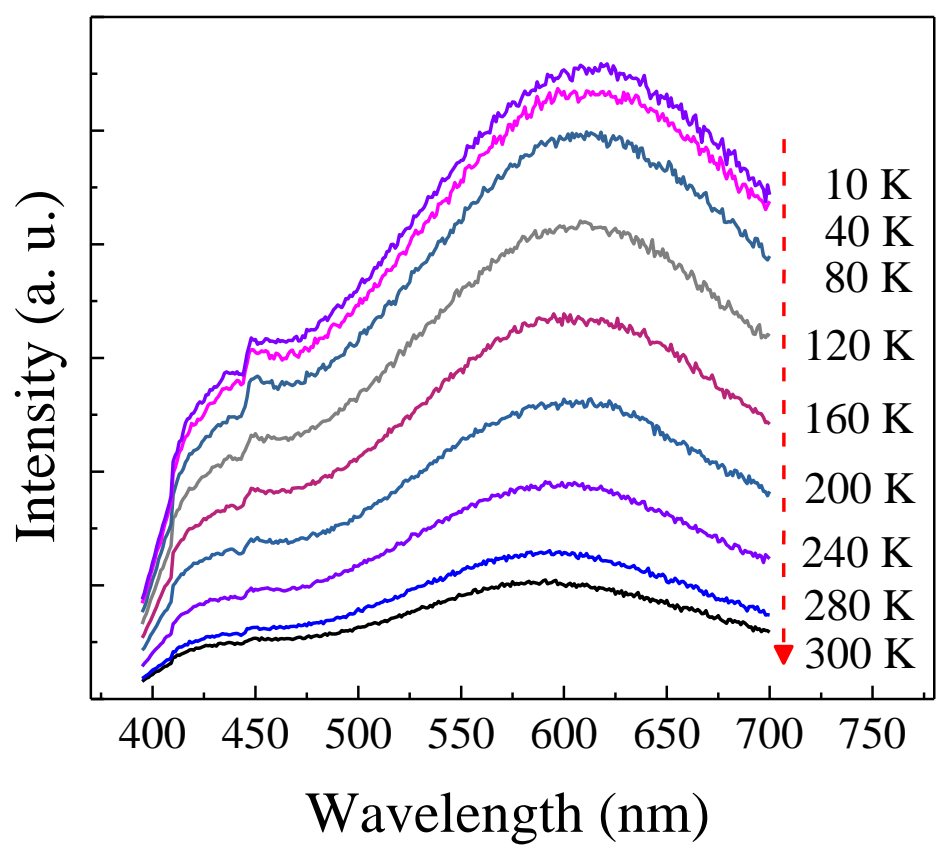

Figure 7. PL spectra measured at different temperatures ranging from $10 \mathrm{~K}$ to $300 \mathrm{~K}$.

\section{Conclusions}

In summary, the effect of thermal annealing on the luminescent a-SiNx containing dense Si nanodots was investigated. Thermal annealing of the films remarkably improved the PL intensity by more than twofold compared with the pristine sample. The PL features a recombination dynamic on a nanosecond timescale. Based on the PL results and the analyses of Raman spectra and the bonding configurations of the samples, the enhanced green emission was attributed to the increased density of radiative centers related to the $\mathrm{Si}$ dangling bonds $(\mathrm{K} 0)$ and $\mathrm{N}_{4}{ }^{+}$or $\mathrm{N}_{2}{ }^{0}$ as a result of bonding configuration reconstruction. 


\begin{abstract}
Author Contributions: Q.L.: writing—original draft preparation, investigation, formal analysis, X.C.: investigation, formal analysis, H.L.: writing—review, formal analysis, Y.G.: investigation, formal analysis. J.S.: investigation. C.S.: investigation. W.Z.: investigation. R.H.: investigation, formal analysis, writing—review. Z.L.: formal analysis, writing—review. All authors have read and agreed to the published version of the manuscript.

Funding: This work was supported by Guangdong Basic and Applied Basic Research Foundation (2020A1515010432), Project of Educational Commission of Guangdong Province of China (2019KTSCX096), Program of Hanshan Normal University (XN201918), Special Funds for the Cultivation of Guangdong College Students' Scientific and Technological Innovation ("Climbing Program" Special Funds) (pdjh2020b0378), Young Talents in Higher Education of Guangdong (2016KQNCX100), and Science and Technology Planning Projects of Chaozhou (2018GY18).
\end{abstract}

Data Availability Statement: Data underlying the results presented in this paper are not publicly available at this time but may be obtained from the authors upon reasonable request.

Conflicts of Interest: The authors declare no conflict of interest.

\title{
References
}

1. Lin, G.R.; Lin, C.J.; Lin, C.K.; Chou, L.J.; Chueh, Y.L. Oxygen defect and Si nanocrystal dependent white-light and near-infrared electroluminescence of Si-implanted and plasma-enhanced chemical-vapor deposition-grown Si-rich $\mathrm{SiO}_{2}$. J. Appl. Phys. 2005, 97, 094306. [CrossRef]

2. Mu, W.; Pei, Z.; Xu, J.; Sun, S.; Jie, X.; Li, W.; Chen, K. Direct-current and alternating-current driving Si quantum dots-based light emitting device. IEEE J. Sel. Top. Quantum Electron. 2013, 20, 206-211.

3. Cheng, C.H.; Lien, Y.C.; Wu, C.L.; Lin, G.R. Mutlicolor electroluminescent Si quantum dots embedded in SiOx thin film MOSLED with $2.4 \%$ external quantum efficiency. Opt. Exp. 2013, 21, 391-403. [CrossRef] [PubMed]

4. Huang, R.; Lin, Z.; Lin, Z.; Song, C.; Wang, X.; Guo, Y.; Song, J. Suppression of hole overflow and enhancement of light emission efficiency in Si quantum dots based silicon nitride light emitting diodes. IEEE J. Sel. Top. Quantum Electron. 2014, $20,8200306$. [CrossRef]

5. Limpens, R.; Luxembourg, S.L.; Weeber, A.W.; Gregorkiewicz, T. Emission efficiency limit of Si nanocrystals. Sci. Rep. 2016, 6, 19566. [CrossRef] [PubMed]

6. Wang, L.; Li, Q.; Wang, H.Y.; Huang, J.C.; Zhang, R.; Chen, Q.D.; Xu, H.L.; Han, W.; Shao, Z.Z.; Sun, H.B. Ultrafast optical spectroscopy of surface-Modified silicon quantum dots: Unraveling the underlying mechanism of the ultrabright and colortunable photoluminescence. Light Sci. Appl. 2015, 4, e245. [CrossRef]

7. Lin, G.R.; Pai, Y.H.; Lin, C.T.; Chen, C.C. Comparison on the electroluminescence of Si-rich SiNx and SiOx based light-emitting diodes. Appl. Phys. Lett. 2010, 96, 263514. [CrossRef]

8. Wang, F.; Li, D.; Yang, D.; Que, D. Enhancement of light-extraction efficiency of SiNx light emitting devices through a rough Ag island film. Appl. Phys. Lett. 2012, 100, 031113. [CrossRef]

9. Lin, Z.; Chen, K.; Zhang, P.; Xu, J.; Li, W.; Yang, H.; Huang, X. Improved Power Efficiency in Phosphorus Doped na-SiNxOy/p-Si Heterojunction Light Emitting Diode. Appl. Phys. Lett. 2017, 110, 081109. [CrossRef]

10. Ma, L.B.; Song, R.; Miao, Y.M.; Li, C.R.; Wang, Y.Q.; Cao, Z.X. Blue-violet photoluminescence from amorphous Si-in-SiNx thin films with external quantum efficiency in percentages. Appl. Phys. Lett. 2006, 88, 093102. [CrossRef]

11. Huang, R.; Song, J.; Wang, X.; Guo, Y.Q.; Song, C.; Zheng, Z.H.; Wu, X.L.; Chu, P.K. Origin of strong white electroluminescence from dense Si nanodots embedded in silicon nitride. Opt. Lett. 2012, 37, 692-694. [CrossRef] [PubMed]

12. Wang, M.; Xie, M.; Ferraioli, L.; Yuan, Z.; Li, D.; Yang, D.; Pavesi, L. Light emission properties and mechanism of low-temperature prepared amorphous SiNX films. I. Room-temperature band tail states photoluminescence. J. Appl. Phys. 2008, 104, 083504. [CrossRef]

13. Negro, L.D.; Yi, J.H.; Kimerling, L.C.; Hamel, S.; Williamson, A.; Galli, G. Light emission from silicon-rich nitride nanostructures. Appl. Phys. Lett. 2006, 88, 183103. [CrossRef]

14. Pi, X.; Chen, X.; Ma, Y.; Yang, D. Optical absorption and emission of nitrogen-doped silicon nanocrystals. Nanoscale 2011, 3 , 4584-4588. [CrossRef] [PubMed]

15. Zhang, H.; Xu, Z. Structural and optical properties of four-hexagonal polytype nanocrystalline silicon carbide films deposited by plasma enhanced chemical vapor deposition technique. Thin Solid Films 2004, 446, 99. [CrossRef]

16. Huang, R.; Lin, Z.; Guo, Y.; Song, C.; Wang, X.; Song, J.; Lin, H.; Xu, L.; Li, H. Bright red, orange-yellow and white switching photoluminescence from silicon oxynitride films with fast decay dynamics. Opt. Mater. Express 2014, 4, 205-212. [CrossRef]

17. Lin, Z.; Huang, R.; Wang, H.; Wang, Y.; Zhang, Y.; Guo, Y.; Song, J.; Song, C.; Li, H. Dense nanosized europium silicate clusters induced light emission enhancement in Eu-doped silicon oxycarbide films. J. Alloys Compd. 2017, 694, 946-951. [CrossRef]

18. Roberson, J.; Powell, M.J. Gap states in silicon nitride. Appl. Phys. Lett. 1984, 44, 415-417. [CrossRef] 